\title{
Originals
}

\section{Accelerated gastric emptying of glucose in Zucker type 2 diabetic rats: role in postprandial hyperglycaemia}

\author{
G.M. G reen ${ }^{1}$, D. G uan ${ }^{1}$, J . G. Schwartz ${ }^{2}$, W.T. Phillips ${ }^{3}$ \\ ${ }^{1}$ D epartment of Physiology, The U niversity of Texas H ealth Science Center at San A ntonio, San A ntonio, Texas, U SA \\ ${ }^{2}$ D epartment of Pathology, The U niversity of Texas H ealth Science Center at San A ntonio, San A ntonio, Texas, U SA \\ ${ }^{3}$ D epartment of R adiology, The U niversity of Texas H ealth Science Center at San A ntonio, San A ntonio, Texas, U SA
}

Summary Patients with early non-insulin-dependent diabetes mellitus (NID D M ) empty glucose solutions from their stomachs more rapidly than non-diabetic control subjects, and this exacerbates postprandial hyperglycaemia.To determine if accelerated gastric emptying occurred in a rat model of NIDDM and influenced postprandial hyperglycaemia, gastric emptying of glucose was measured, and the effect of slowing the gastric emptying rate on postprandial hyperglycaemia was observed. We tested eight male obese Zucker diabetic rats and eight age-matched lean Zucker controls at 10-13 weeks of age to measure gastric emptying of glucose (by gamma scintigraphy). R ats fasted overnight were gavaged with $30 \%$ glucose at $1 \mathrm{ml} / 100 \mathrm{~g}$ body weight. Separately, six Zucker diabetic rats and six lean controls were tested for sensitivity to the inhibitory effects of cholecystokinin and secretin on gastric emptying. The diabetic rats emptied glucose significantly faster than controls $\left(\mathrm{t}_{1 / 2}=37.3 \pm 1.5\right.$ vs $58.8 \pm 2.3 \mathrm{~min}$ in controls $)$, and aging exaggerated this differential. Camostat, a stimulant of cholecystokinin and secretin release, added to the glucose meal significantly slowed gastric emptying $\left(\mathrm{t}_{1 / 2}=123 \pm 23\right.$ and $166 \pm 19$ min, diabetic vs lean, respectively), and significantly reduced postprandial hyperglycaemia in diabetic rats. Compared to Z ucker lean controls, Z ucker diabetic rats were as sensitive (cholecystokinin) or more sensitive (secretin) to gastrointestinal hormones that inhibit gastric emptying. The results demonstrate accelerated gastric emptying in a rat model of NID D M, consistant with similar observations in humans with early NIDDM. These results also support the proposal that interventions to slow gastric emptying may improve glucose control in this disease. [D iabetologia (1997) 40: 136-142]

Keywords Cholecystokinin, secretin, trypsin inhibitor, glycaemic control, gastric emptying.
Phillips et al. [1] demonstrated abnormally rapid gastric emptying of glucose solutions in patients with recently diagnosed non-insulin-dependent diabetes mellitus (NID D M ), which contrasts with delayed gastric emptying (gastroparesis), a well-documented late manifestation of diabetes attributed to autonomic

Received: 11 July 1995 and in final revised form: 110 ctober 1996

Corresponding author: D r. G.M . G reen, D epartment of Physiology, U niversity of Texas $\mathrm{H}$ ealth Science Center at San A ntonio, 7703 Floyd Curl Drive, San A ntonio, TX 78284-7756, USA

A bbreviations: CCK, Cholecystokinin; NIDDM, Non-insulindependent diabetes mellitus; ID D M , insulin-dependent diabetes mellitus. neuropathy [2]. Intravenous administration of cholecystokinin (CCK), a physiological inhibitor of gastric emptying in healthy humans [3], normalized gastric emptying of a glucose test meal in NIDDM diabetic patients and reduced the postprandial hyperglycaemia [4]. This outcome was predicted from studies in healthy human subjects which showed that CCK regulated postprandial blood glucose levels by slowing gastric emptying [5]. These studies support the hypothesis [1] that accelerated gastric emptying in early N ID D M in humans may contribute to poor glucose control by increasing the rate of glucose entry into the small intestine, thereby increasing absorption rate and exacerbating postprandial hyperglycaemia.

To further examine this phenomenon, the gastric emptying of glucose was investigated in a newly 
developed rat model of NIDDM $[6,7]$. In addition, the effect of treatment with a synthetic trypsin inhibitor (camostat), on gastric emptying of glucose and postprandial hyperglycaemia was determined. Camostat is a strong stimulant of CCK and secretin release $[8,9]$ and an inhibitor of gastric emptying $[10]$ in rats.

\section{Materials and methods}

A nimals. $R$ ats used in this study were: 1$)$ the partially inbred Zucker diabetic fatty male rat (ZDF/G mi ${ }^{\mathrm{TM}}$-fa/fa), a recently developed NIDDM model with a Zucker background and the fa gene; and 2) the partially inbred Zucker lean male (ZDF/ $\mathrm{G} \mathrm{mi}^{\mathrm{TM}},+/+$ or + /fa genotype). Both were obtained from Genetic Models, Inc. (Indianapolis, Ind., USA), at age 56 weeks. A ccording to the supplier, the diabetic fatty male rats usually manifest hyperglycaemia at about 7 weeks of age and are fully diabetic by 10 weeks of age (postprandial blood glucose levels of $>27 \mathrm{mmol} / \mathrm{l}$ ). B etween $7-10$ weeks of age, blood insulin levels are elevated but subsequently drop as the pancreatic beta cells cease to respond to the glucose stimulus $[6,7]$. Procedures used with animals in this study were approved by the U niversity Institutional A nimal Care and U se Committee.

A II rats were maintained on Purina Formulab 5008 rat chow (St. L ouis, M O, U SA ) throughout the study ( $23.5 \%$ protein, $49.4 \%$ carbohydrate, $6.5 \%$ fat), and were housed in a climate-controlled room in individual plastic cages with raised wire floors. The lights-off period was from 21.00 to 07.00 hours.

Materials. Camostat (also known as FOY-305), a synthetic trypsin inhibitor, was provided by 0 no Pharmaceuticals, O saka, Japan. CCK -8 and synthetic rat secretin were obtained from Peninsula L aboratories, B elmont, Calif., USA .

Procedures. G astric emptying rate was measured by gamma scintigraphy at 20 or 30 min intervals in awake rats. A fter a 12-h fast, rats were administered by gavage $30 \%$ glucose $(1.67 \mathrm{~mol} / \mathrm{l}, 1.2 \mathrm{kcal} / \mathrm{ml})$ in water containing $200 \mu \mathrm{Ci}$ of technetium-99m sulfur colloid (99mT c-SC), and then held for $10 \mathrm{~s}$ in a prone position on top of a gamma camera. The solution was administered at $1 \mathrm{ml} / 100 \mathrm{~g}$ body weight $(12 \mathrm{kcal} / \mathrm{kg}$ body weight). I mages were acquired using a low energy, all-purpose collimator with a $20 \%$ energy window setting centred at 140 $\mathrm{keV}$. The camera was connected to a Pinnacle N uclear Workstation (M edasys, Inc., A nn A rbor, M ich., USA ). R egions of interest were drawn around the stomach for all images acquired, by an investigator blinded to the treatment and group. $B$ aseline counts (per $10 \mathrm{~s}$ ) in the stomach region after gavage of the glucose solution were approximately 12000 . In the week prior to carrying out experiments, rats were adapted to the brief restraint period (10 s) necessary for acquiring the images.

Studies were carried out in eight Z ucker diabetic fatty rats and eight Zucker lean controls when the rats were 1013 weeks old to determine rate of gastric emptying of glucose and the effect of delaying gastric emptying on postprandial hyperglycaemia. Additional experiments were performed to study the effect of age and duration of the diabetic state on gastric emptying of glucose. These were done at 6 weeks of age, before they developed elevated plasma glucose, 10 weeks of age, and at 18 weeks of age, when the diabetic state was advanced. In a separate experiment, the effect of exogenous cholecystokinin (CCK -8) and secretin on gastric emptying was studied in an additional six Zucker diabetic and six Z ucker lean rats.

In studies carried out at approximately 10 weeks of age, eight diabetic and eight lean rats were gavaged with $30 \%$ glucose alone, and gastric emptying rate determined. At 1213 weeks of age, the effect of camostat on gastric emptying of glucose and on postprandial plasma glucose was determined. Camostat was added to the glucose solution at a concentration of $10 \mathrm{mg} / \mathrm{ml}(1 \%)$. For this study, the gastric emptying rate for the $30 \%$ glucose solution was again determined, but with and without the addition of camostat. $R$ ats received treatments in a crossover design such that half the rats in each group (fatty or lean) received glucose and camostat treatment and the remaining half received glucose alone, and this order was reversed 1 week later. Plasma glucose concentration was determined before infusion of test meals (fasting levels) and at 15min intervals up to 90 min postprandially. To determine the plasma glucose concentration, $50 \mu \mathrm{l}$ of blood was collected from the tail vein and analysed by the glucose oxidase method (Sigma Diagnostics, St.Louis, M O, USA) on duplicate 5- $\mu$ l samples of plasma. Sampling required only very mild restraint of the rats.

To determine whether accelerated gastric emptying in Zucker diabetic rats might be due to decreased sensitivity to CCK or secretin, hormones known to inhibit gastric emptying, a second group of six Zucker diabetic and six Zucker lean rats, $12-14$ weeks of age, were fed the same $30 \%$ glucose test meal already described and the effect of CCK -8 or secretin on gastric emptying of the meal was determined. Diabetic and lean rats were randomly assigned to experimental groups receiving the test meal with CCK, secretin, or vehicle, with each experiment separated by 4 days. CCK $-8(3 \mu \mathrm{g} / \mathrm{kg})$ and secretin $(5 \mu \mathrm{g} / \mathrm{kg})$ were administered i. p. immediately after gavage of the test meal (time 0 ) and after each imaging session (30-min intervals) up to and including the 90-min image. These dose levels of CCK -8 and secretin were found in preliminary trials to be maximally effective doses for inhibiting stomach emptying.

A nalysis of data. Gastric emptying was expressed as percentage of gastric contents remaining vs time from 0 to $120 \mathrm{~min}$. Rates of gastric emptying were compared by determining half-emptying times $\left(t_{1 / 2}\right)$ and by determining area under the curve (AUC) (numerical integration of values from 0 to $120 \mathrm{~min}$ ) calculated using the trapezoid rule. Comparisons of values for A U C were analysed where appropriate either by paired or unpaired t-test, or by A N OVA with post-hoc analysis using Fisher's protected least significant difference. Gastric half-emptying time for each rat was determined by fitting the data to a power exponential curve using non-linear least squares regression [11]. Effect of camostat on increment of plasma glucose concentration was analysed by two-way A NO VA with repeated measures. For statistical comparisons of values of $t_{1 / 2}$, means were considered significantly different from each other if the $95 \%$ confidence intervals generated by nonlinear regression did not overlap. For gastric emptying studies in which the calculated $t_{1 / 2}$ greatly exceeded the experimental period, the $95 \%$ confidence intervals for $t_{1 / 2}$ generated by non-linear regression become very large, and A U C was considered a more suitable comparison.

The changes in gastric emptying rate with age in lean and diabetic rats are expressed in two ways, as $t_{1 / 2}$ values and as kcal emptied per h per kg body weight. The latter rate was calculated from $t_{1 / 2}$ values and is simply the average rate of emptying of caIories ( $\left.\mathrm{kcal} \cdot \mathrm{kg}^{-1} \cdot \mathrm{h}^{-1}\right)$ up to the time when half the meal has emptied (i.e. the $t_{1 / 2}$ ). This additional expression is useful because $t_{1 / 2}$ values alone do not convey this information if the 
initial size of the meal is different between groups, which was the case because meal size was based on body weight which varied with age and whether the rats were diabetic or lean.

\section{Statistical analysis}

R esults are presented as mean \pm SE M, and were considered statistically significant if $p$ was less than 0.05 .

\section{Results}

Body weight of Zucker fatty and lean rats. Table 1 shows the body weights of both groups of rats at 6 , $10,12-13$, and 18 weeks. By 18 weeks, lean rats had overtaken the diabetic fatty rats in body weight.

Gastric emptying of $30 \%$ glucose in 10 -week-old Zucker lean and diabetic rats. A t 10 weeks of age, gastric emptying of the glucose test meal was significantly accelerated in Zucker diabetic fatty rats compared to lean rats (Fig. 1). The gastric half-emptying time $\left(t_{1 / 2}\right)$ was $37.3 \pm 1.5 \mathrm{~min}$ in diabetic rats and $58.8 \pm 2.3 \mathrm{~min}$ in lean rats. The A U C for diabetic rats was significantly lower when compared to lean rats (4824 \pm 234 vs $6299 \pm 367$, diabetic vs lean, respectively). A nalysis of the gastric emptying curves showed that diabetic rats emptied predominately in an exponential fashion, whereas lean rats emptied the glucose solution in a primarily linear fashion. Converting $t_{1 / 2}$ to calories emptied per $\mathrm{kg}$ body weight per $h$, diabetic rats emptied at 9.64, compared to $6.12 \mathrm{kcal} \cdot \mathrm{kg}^{-1} \cdot \mathrm{h}^{-1}$ for lean rats.

E ffect of camostat on gastric emptying of $30 \%$ glucose in Zucker diabetic and lean rats. The effect of camostat on gastric emptying of glucose in Zucker diabetic and lean rats carried out at 12-13 weeks of age is illustrated in Figure 2. Camostat significantly slowed gastric emptying of glucose in Zucker diabetic rats, yielding a gastric half-emptying time of $123 \pm 23 \mathrm{~min}$ with camostat, and $42.0 \pm 2.8 \mathrm{~min}$ in the absence of camostat. The A U C was significantly increased (by $49 \%$ ) with camostat ( $8038 \pm 653$ vs $5407 \pm 407$ ). The same effect was also seen in lean rats, with camostat significantly slowing gastric emptying $\left(t_{1 / 2}=166 \pm 19\right.$ vs $79.1 \pm 4.4 \mathrm{~min}$ ), but to a lesser degree than in diabetic rats. The A U C in lean rats was significantly increased by camostat $(9036 \pm 273$ vs $7475 \pm 423)$. In the absence of camostat, diabetic rats emptied significantly faster than lean rats, but when both groups were treated with camostat there was no significant difference between diabetic and lean rats in gastric half-emptying times ( $123 \pm 23$ vs $166 \pm 19 \mathrm{~min}$, diabetic vs lean, respectively).

Incremental plasma glucose concentrations following the glucose meal are shown in Figure 3. Results are expressed as the increment above fasting
Table 1. B ody weights (g) of Zucker lean and diabetic rats at different ages

\begin{tabular}{lllll}
\hline & $\begin{array}{l}6 \text { weeks } \\
(\mathrm{n}=4)\end{array}$ & $\begin{array}{l}10 \text { weeks } \\
(\mathrm{n}=8)\end{array}$ & $\begin{array}{l}12-13 \text { weeks } \\
(\mathrm{n}=8)\end{array}$ & $\begin{array}{l}18 \text { weeks } \\
(\mathrm{n}=4)\end{array}$ \\
\hline Lean & $156 \pm 6.0^{\mathrm{a}}$ & $295 \pm 5.9^{\mathrm{a}}$ & $312 \pm 6.9^{\mathrm{a}}$ & $\begin{array}{l}432 \pm 15 \\
411 \pm 16\end{array}$ \\
\hline Diabetic & $200 \pm 1.6$ & $365 \pm 8.9$ & $382 \pm 5.6$ & $411 \pm 0$ \\
\hline
\end{tabular}

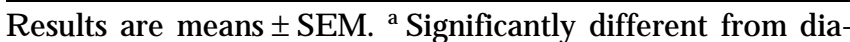
betic group of same age $(p<0.05$, unpaired t-test)

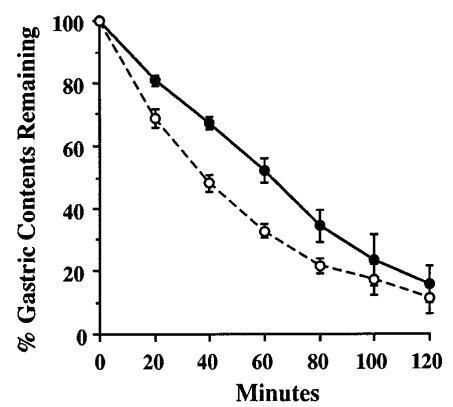

Fig. 1. G astric emptying of a glucose test meal in Z ucker type II diabetic rats (O) and $Z$ ucker lean rats (O). R ats ( 10 weeks old) were gavaged with $30 \%$ glucose in water $(1 \mathrm{ml} / 100 \mathrm{~g}$ body weight) and gastric emptying was monitored by gamma scintigraphy. $G$ astric emptying was significantly $(p<0.05)$ accelerated in diabetic rats as indicated by a $37 \%$ decrease in half-emptying time $\left(t_{1 / 2}=37.3 \pm 1.5\right.$ vs $58.8 \pm 2.3 \mathrm{~min}$, diabetic vs lean, respectively) and $23 \%$ decrease in A U C. R esults are mean \pm SE $M$ for eight rats in each group

values. A s was expected, fasting plasma glucose concentrations for Z ucker diabetic rats were markedly and significantly elevated compared to Zucker lean rats $(13.2 \pm 0.91$ vs $5.56 \pm 0.21 \mathrm{mmol} / \mathrm{l}$, diabetic vs lean, respectively). Fasting plasma glucose values were not different between camostat-treated and untreated rats. In camostat-treated diabetic rats, the increment in plasma glucose was non-significantly $(p=0.07)$ increased approximately twofold at 15 and 30 min postprandial, and was significantly increased 1.60 -fold at $60 \mathrm{~min}$ postprandial. Lean Zucker rats displayed a much more modest increase in plasma glucose following the glucose meal, and camostat treatment had virtually no effect on their postprandial plasma glucose values.

E ffect of CCK and secretin on gastric emptying of $30 \%$ glucose in Zucker diabetic and lean rats. The effects of CCK-8 and secretin on gastric emptying curves are illustrated in Figure 4, and corresponding $t_{1 / 2}$ values are presented in Table 2 . Differences in the emptying curves in this experiment are stated as significant if either $t_{1 / 2}$ or $A \cup C$ were significantly different statistically. A s expected, in absence of CCK -8 or secretin treatment, diabetic rats emptied the glucose meal faster than lean rats (significant for $t_{1 / 2}$ and $A \cup C$ ). CCK -8 slowed gastric emptying in diabetic and lean rats (significant for $t_{1 / 2}$ of 

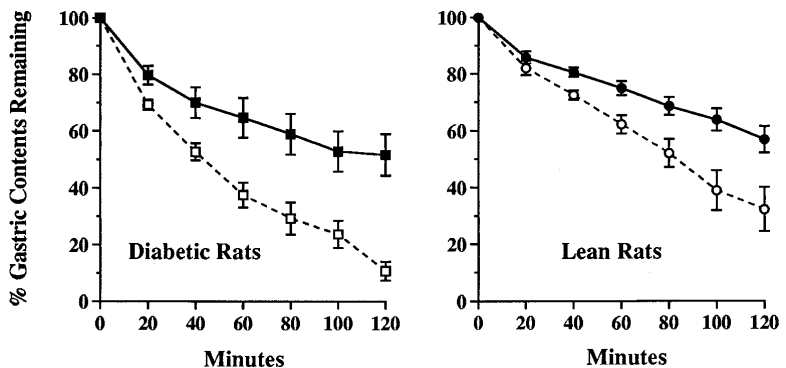

Fig. 2. E ffect of protease inhibitor (camostat) on gastric emptying of glucose in Zucker type II diabetic rats (left panel) and lean rats (right panel), at 12-13 weeks of age. Glucose (30\% ) containing $1 \%$ camostat was fed by gavage at $1 \mathrm{ml} / 100$ $\mathrm{g}$ body weight and stomach emptying monitored by gamma scintigraphy. Camostat $(\square, 0)$ significantly $(p<0.05)$ slowed gastric emptying of glucose as indicated by a $293 \%$ increase in $t_{1 / 2}$ in diabetic rats and a $210 \%$ increase in $t_{1 / 2}$ in lean rats. The $t_{1 / 2}$ values in control (non-camostat treated; $(\square, O)$ rats were significantly different $(p<0.05)$ between diabetic and lean rats $(n=8)$

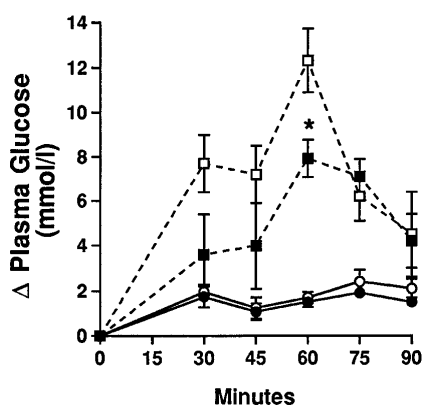

Fig. 3. E ffect of protease inhibitor (camostat) on incremental increase in plasma glucose concentrations in 6 Zucker type II diabetic rats $(\square, \square)$ and 6 lean rats $(O, 0)$ at $12-13$ weeks of age. G lucose $(30 \%)$ containing $1 \%$ camostat was fed by gavage at $1 \mathrm{ml} / 100 \mathrm{~g}$ body weight and blood was taken from the tail vein at 15-min intervals for glucose determination. Camostat $(\square, 0)$ significantly $(p<0.05)$ reduced the increment in plasma glucose concentration at the 60 min interval in diabetic rats

diabetic rats). Secretin significantly (A U C) slowed gastric emptying in both diabetic and lean rats, but in diabetic rats, the inhibition caused by secretin was significantly ( $A \cup C$ ) greater than that caused by CCK-8.

Changes in gastric emptying with age in Zucker fatty and lean rats. In this study, gastric emptying of the $30 \%$ glucose test meal was measured at 6 weeks, 10 weeks, and 18 weeks. The rate of gastric emptying of $30 \%$ glucose is illustrated in Figure 5 and mathematically expressed in Table 3 , both as $t_{1 / 2}$ and as $\mathrm{kcal} \cdot \mathrm{kg}^{-1} \cdot \mathrm{h}^{-1}$. A t 6 weeks of age, there was no apparent difference in rate of gastric emptying between lean and fatty rats. B y 10 weeks of age the differences were clear and statistically significant, and by 18 weeks, the differences in rate of emptying were
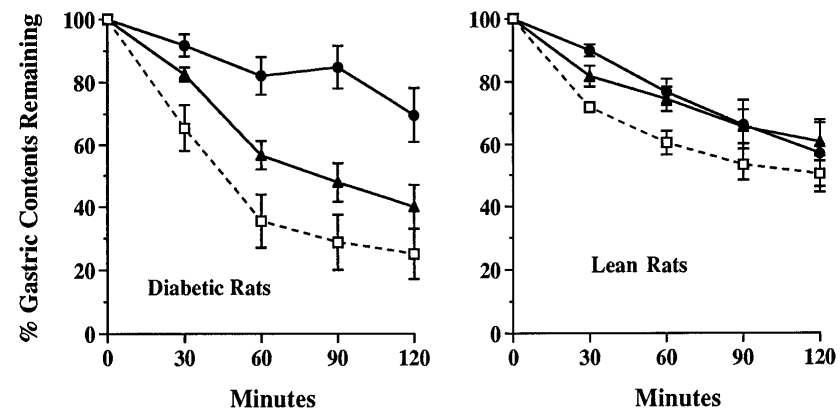

Fig. 4. E ffect of CCK-8 and secretin on gastric emptying of glucose in 6 Zucker type II diabetic rats (left panel) and 6 Zucker lean rats (right panel) at 12-13 weeks of age. G lucose $(30 \%$ ) was fed by gavage at $1 \mathrm{ml} / 100 \mathrm{~g}$ body weight and stomach emptying monitored by gamma scintigraphy. CCK-8 $(3 \mu \mathrm{g} / \mathrm{kg}, \boldsymbol{\Delta})$, secretin $(5 \mu \mathrm{g} / \mathrm{kg}, \quad \mathrm{O})$, or $0.15 \mathrm{~mol} / \mathrm{l} \mathrm{NaCl}$ $(\cdots \cdot \square \cdots)$ was injected i. p. at time 0 and repeated at 30-min intervals. CCK -8 and secretin significantly slowed gastric emptying in diabetic rats. CCK -8 and secretin were equally effective in slowing gastric emptying in lean rats (significant for secretin), whereas secretin was significantly more effective than CCK -8 in slowing gastric emptying in diabetic rats

dramatic, with diabetic rats emptying more than six times faster than lean rats. This very large difference at 18 weeks of age occurred due to the slowing of emptying in lean rats and acceleration of emptying in diabetic rats, compared to earlier ages.

\section{Discussion}

A ccelerated gastric emptying in diabetes is little recognized, but well demonstrated. It has been reported in humans both in early NIDDM [1, 4], and in insulin-dependent diabetic (IDDM) patients who were asymptomatic for gastrointestinal dysfunction [12]. In rats, accelerated gastric emptying of liquid or solid meals was previously demonstrated in several models of IDDM [13, 14]. The present study represents the first report, to our knowledge, of this phenomenon in an animal model of NIDDM.

Intravenous CCK at physiological doses normalized the accelerated gastric emptying rates in patients with NIDDM [4] and improved indices of glucose control, i.e. postprandial blood glucose and insulin values were lowered. Therefore, it seemed worthwhile to establish an appropriate animal model to test compounds known to release endogenous CCK for their ability to slow gastric emptying and improve postprandial hyperglycaemia in NIDDM. Camostat inhibited gastric emptying in conventional, non-diabetic rats via a CCK-dependent mechanism [10], but this has not been studied in rat models of IDDM or NIDDM. Furthermore, camostat stimulates secretin release in the rat [9], and secretin inhibits gastric emptying in conventional, nondiabetic rats $[15,16]$. In the present study, camostat 
Table 2. Rate of gastric emptying of glucose in Zucker lean and Z ucker fatty rats at different ages $(n=4)$

\begin{tabular}{lccc}
\hline & 6 weeks old & 10 weeks old & 18 weeks old \\
\hline$\left(\mathrm{t}_{1 / 2}\right)$ & $78.2 \pm 4.2^{\mathrm{a}}$ & $57.5 \pm 3.6^{\mathrm{a}}$ & $179 \pm 14^{\mathrm{a}}$ \\
Lean & & & \\
Fatty (diabetic) & $70.8 \pm 2.6^{\mathrm{b}}$ & $39.2 \pm 2.4^{\mathrm{ab}}$ & $28.1 \pm 4.8^{\mathrm{ab}}$ \\
$\left(\mathrm{kcal} \cdot \mathrm{kg}^{-1} \cdot \mathrm{h}^{-1}\right)$ & & & \\
Lean & $4.60 \pm 0.25^{\mathrm{a}}$ & $6.26 \pm 0.39^{\mathrm{a}}$ & $2.02 \pm 0.16^{\mathrm{a}}$ \\
Fatty (diabetic) & $5.09 \pm 0.19^{\mathrm{b}}$ & $9.18 \pm 0.57^{\mathrm{ab}}$ & $12.82 \pm 2.21^{\mathrm{ab}}$ \\
\hline
\end{tabular}

For $\mathrm{t}_{1 / 2}$ values (upper table) or for $\mathrm{kcal} \cdot \mathrm{kg}^{-1} \cdot \mathrm{h}^{-1}$ values (lower table), means sharing a common superscript (within a row or within a column) are significantly different from each other. Values are means \pm SE M

Table 3. E ffect of secretin and cholecystokinin on gastric emptying of glucose in Z ucker diabetic and Z ucker lean rats $(n=6)$

\begin{tabular}{|c|c|c|}
\hline & Diabetic $\quad\left(t_{1 / 2}\right)$ & Lean \\
\hline $\begin{array}{l}\text { Control }(0.15 \mathrm{~mol} / / \mathrm{NaCl}) \\
\text { CCK }-8(3 \mu \mathrm{g} / \mathrm{kg}) \\
\text { Secretin }(5 \mu \mathrm{g} / \mathrm{kg})\end{array}$ & $\begin{array}{r}45.7 \pm 7.5^{\mathrm{a}} \\
85.6 \pm 6.4^{\mathrm{a}} \\
233 \pm 131\end{array}$ & $\begin{array}{l}114 \pm 17^{a} \\
193 \pm 52 \\
204 \pm 57\end{array}$ \\
\hline
\end{tabular}

$D$ ata are expressed as $t_{1 / 2}$ determined by non-linear least squares regression. $R$ ats fasted overnight were fed by gavage a $30 \%$ glucose solution at $1 \mathrm{ml} / \mathrm{kg}$ body weight. I mmediately after feeding they were injected i.p. with CCK -8, secretin, or vehicle $(0.15 \mathrm{~mol} / \mathrm{I} \mathrm{N} \mathrm{aCl})$, and the injections were repeated at each subsequent imaging interval (30-min intervals). M eans sharing a common superscript (within a row or within a column) are significantly different from each other. Values are means $\pm S E M$ for 6 rats in each group
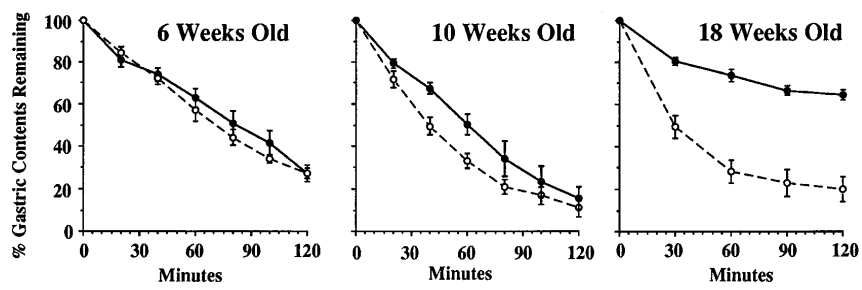

Fig. 5. Comparison of gastric emptying of glucose at different ages in Z ucker type II diabetic rats (O) and Zucker lean rats (O). $R$ ats were fed $30 \%$ glucose at $1 \mathrm{ml} / 100 \mathrm{~g}$ body weight as described in Fig. $1(n=4)$. (Body weights shown in Table 1 . Statistical analysis of data shown in Table 3.) The differential in rate of gastric emptying between diabetic and lean rats was negligible at 6 weeks of age, significantly different at 10 weeks of age, and greatly exaggerated at 18 weeks of age

significantly inhibited gastric emptying in both diabetic and in lean Zucker rats and significantly reduced postprandial plasma glucose in the diabetic rats. Therefore, we suggest that camostat inhibited gastric emptying via increased CCK or secretin release, although the present study does not define the role of either of these hormones in the inhibition of gastric emptying caused by camostat in the diabetic rats.

The absence of an effect of camostat on plasma glucose levels in Z ucker lean rats, despite substantial slowing of gastric emptying in the same rats, indicates that mechanisms controlling gastric emptying in normal, healthy animals result in a controlled rate of emptying of carbohydrate consistent with highly efficient disposal of glucose.

The cause of rapid gastric emptying in NIDDM is not known. Rushak off et al. [17] reported that CCK release in response to a high calorie, mixed meal was markedly attenuated in NIDDM patients, suggesting that accelerated gastric emptying in diabetes may be due to insufficient CCK release, resulting in loss of an important feedback control of gastric emptying. On the other hand, G lasbrenner et al. [18] recently reported elevated postprandial CCK levels in diabetic patients (IDDM and NIDDM), which were most pronounced in those patients with autonomic neuropathy. In preliminary studies [19], we found that basal plasma CCK levels and basal and postprandial plasma secretin levels were significantly elevated in Zucker type II diabetic rats. Therefore, acceleration of gastric emptying in diabetic rats does not appear to be due to a deficiency in CCK or secretin release.

A ccelerated gastric emptying coincident with elevated plasma CCK or secretin levels might suggest that gastric emptying in diabetes is resistant to the effects of CCK or secretin. This would fit with a body of evidence indicating that Z ucker (non-diabetic) obese rats are resistant to some effects of CCK, in particular, appetite suppression and exocrine pancreatic secretion [20-22]. In the present study, however, Z ucker diabetic rats were at least as sensitive as lean rats to the inhibitory effects on gastric emptying of exogenous CCK-8 and oral trypsin inhibitor, and were markedly more sensitive to secretin in this respect. Therefore, accelerated gastric emptying in diabetic rats cannot be explained by a decreased sensitivity of gastric emptying to either CCK or secretin. On the other hand, elevated plasma CCK and secretin levels in Zucker diabetic rats, described in our preliminary report [19], are consistent with reduced exocrine pancreas sensitivity to these hormones, because both CCK and secretin secretion are controlled by pancreatic proteases in the intestine in a negative feedback manner $[9,23]$.

The above discussion begs the question, if endogenous secretin is elevated in Zucker diabetic rats and exogenous secretin is a strong inhibitor of gastric emptying in the same rats, why is gastric emptying not delayed, rather than accelerated, in these rats? The answer may rest with the fact that the dose of exogenous secretin used in this study, although suitable for sensitivity studies, produces supraphysiological plasma secretin concentrations [24]. In contrast, physiological plasma secretin concentrations, even if elevated as in Zucker diabetic rats [19], may not be sufficiently high to counteract the tendency for rapid gastric emptying in these rats. 
O ne conclusion that can be drawn from our results with CCK -8 and secretin is that the accelerated gastric emptying in Zucker diabetic rats is not caused by vagal dysfunction. This is concluded because the inhibitory effects of exogenous CCK and secretin on gastric emptying in the rat require an intact vagal pathway $[15,25]$.

The rate of gastric emptying of glucose was similar between Zucker diabetic rats and lean rats when measured at 6 weeks of age, but was dramatically different when measured at 18 weeks of age (Fig. 5 and Table 2). A t 18 weeks of age, there was a further slowing of gastric emptying in lean rats and a further acceleration of gastric emptying in diabetic rats, compared to their respective rates of emptying at 6 weeks. When expressed as calories emptied/kg body weight (Table 2), the data show that at 18 weeks of age, diabetic rats emptied calories approximately 6.4 times faster than lean rats of the same age.

The progression in calorie-wise rate of gastric emptying with age in Zucker diabetic rats stands in sharp contrast to the data in Zucker lean rats (Table 2). The effect of age per se on gastric emptying has received little attention, but appears to be stable in healthy humans [26]. The stability of this rate with age in healthy, non-diabetic animals seen in the present study is in agreement with the concept that gastric emptying is primarily controlled by calories [27]. Therefore, calorie-wise rate of gastric emptying would not be expected to increase with age in healthy animals, but rather to decline as energy needs per $\mathrm{kg}$ body weight decline with age. I $n$ contrast, the control of gastric emptying in diabetes (in the stage when accelerated gastric emptying is manifested) appears to be less sensitive to glucose calories, and this is exacerbated with age, which may reflect the severity of the loss of glucose homeostasis.

The mechanism for rapid gastric emptying of carbohydrate in diabetes is therefore unclear. Granneman and Stricker [14] speculated that the accelerated gastric emptying in streptozotocin-induced diabetes in rats resulted from more rapid absorption of glucose by the small intestine, thereby reducing intestinal feedback inhibitory signals that slow gastric emptying. R ecently, Y oung et al. [28] presented a novel and intriguing hypothesis to explain accelerated gastric emptying in diabetes. B ased on the discovery that the beta-cell peptide amylin (which is cosecreted with insulin) potently limits the postprandial rise in plasma glucose and is deficient in IDDM, they hypothesized that amylin might be a physiological inhibitor of gastric emptying. They demonstrated that subcutaneous injections of amylin in doses that produced physiological plasma amylin concentrations reversed the accelerated gastric emptying in diabetic $B B$ rats, and potently inhibited gastric emptying in control rats. Based on this demonstration, Young et al. [28] proposed that the rapid gastric emptying associated with diabetes may be due to amylin deficiency.

The hypothesis that rapid gastric emptying in diabetes is due to a deficiency in amylin secretion [28] is appealing, but it cannot explain the acceleration of gastric emptying in NIDDM in rats or humans, because amylin secretion is either unchanged or elevated in NID D M $[29,30]$, in contrast to ID D M . N evertheless, the finding that amylin is a potent inhibitor of gastric emptying suggests that amylin may be a component of accelerated gastric emptying in later stages of NIDDM when beta-cell function declines. This might explain why gastric emptying in 18-weekold diabetic rats (Fig.5) was even more rapid than in 10-week-old diabetic rats in our study, inasmuch as 18-week-old rats may have exhausted their beta-cell function, as evidenced by insulin deficiency at this age (personal communication, Lea Little, Genetic M odels, Inc., Indianapolis, IN, U SA ), and therefore be deficient in amylin secretion.

The ability of oral protease inhibitors to reverse accelerated gastric emptying in a rat model of NIDDM may provide a model for a new treatment of NIDDM in humans. O ral agents such as protease inhibitors may stimulate release of gastrointestinal hormones that normalize the rapid gastric emptying reported in NIDDM patients and reduce postprandial hyperglycaemia and hyperinsulinaemia. Indeed, in recent studies we have found that oral administration of a protease inhibitor (potato protease inhibitor II), to NIDDM patients significantly slowed gastric emptying of a glucose meal and significantly attenuated postprandial hyperglycaemia and hyperinsulinaemia [31]. G ulli et al. [32] have pointed out that hyperglycaemia per se can lead to secondary disturbances in insulin secretion and insulin sensitivity. Therefore, efforts to reduce postprandial hyperglycaemia and hyperinsulinaemia by correcting accelerated gastric emptying in early NIDDM may slow the progression of the disease. Models of human NIDDM, such as the strain of rat described here, may be useful in evaluating the short- and long-term effects of intervention in gastric emptying on glucose control.

A cknowledgements. Supported in part by N IH grant R O I D K 37482 (G.M.G.) and a grant from the South Texas H ealth R esearch Center (J.G.S.). We are grateful to D r. C. Y uan for analysis of gastric emptying data.

\section{References}

1. Phillips WT, Schwartz J G, M cM ahan CA (1992) R apid gastric emptying of an oral glucose solution in type 2 diabetic patients. J N ucl M ed 33: 1496- 1500

2. L oo FD, Palmer DW, Soergel KH, Kalbfleisch JH, Wood CM (1984) G astric emptying in patients with diabetes mellitus. G astroenterology 86: 485-494 
3. Liddle R A, Morita ET, Conrad CK, Williams JA (1986) R egulation of gastric emptying in humans by cholecystokinin. J Clin Invest 77: 992-996

4. Phillips WT, Schwartz J G, M cM ahan CA (1993) R educed postprandial blood glucose levels in recently diagnosed non-insulin-dependent diabetics secondary to pharmacologically induced delayed gastric emptying. D ig D is Sci 38: 51-58

5. Liddle RA, R ushakoff RJ, M orita ET, B eccaria L, Carter JD, G oldfine ID (1988) Physiological role for cholecystokinin in reducing postprandial hyperglycaemia in humans. J Clin Invest 81: 1675-1681

6. Johnson J H , O gawa A , Chen L, et al. (1990) U nderexpression of $\beta$ cell high $\mathrm{K}_{\mathrm{m}}$ glucose transporters in noninsulin-dependent diabetes. Science 250: 546-549

7. Unger RH (1991) Diabetic hyperglycaemia: link to impaired glucose transport in pancreatic $\beta$ cells. Science 251: 1200-1205

8. M iyasaka K, N akamura R, K itani K (1989) E ffects of trypsin inhibitor (camostat) on pancreas and CCK release in young and old female rats. J G erontol 44:M 136-M 140

9. Watanabe S, Takeuchi T, Chey WY (1992) Mediation of trypsin inhibitor-induced pancreatic hypersecretion by secretin and cholecystokinin in rats. G astroenterology 102: 621-628

10. G reen T, D imaline R, Peikin S, D ockray GJ (1988) A ction of the cholecystokinin antagonist $L 364,718$ on gastric emptying in the rat. A m J Physiol 255:G 685-G 689

11. E lashoff J D, M eyer J H, R eedy TJ (1982) A nalysis of gastric emptying data. G astroenterology 83: 1306-1312

12. N owak TV, Johnson CP, K albfleisch J H, et al. (1995) H ighly variable gastric emptying in patients with insulin-dependent diabetes mellitus. G ut 37: 23-29

13. N owak TV, R oza A M, Weisbruch J P, B rosnan M R (1994) A ccelerated gastric emptying in diabetic rodents: effect of insulin treatment and pancreas transplantation. J L ab Clin $M$ ed 123: 110-116

14. Granneman J G, Stricker E M (1984) Food intake and gastric emptying in rats with streptozotocin-induced diabetes. A m J Physiol 247:R 1054-R 1061

15. Raybould HE, Holzer H (1993) Secretin inhibits gastric emptying in rats via a capsaicin-sensitive vagal afferent pathway. E ur J Pharmacol 250: 165-167

16. M urthy SN, G aniban G (1988) E ffect of the secretin family of peptides on gastric emptying and small intestinal transit in rats. Peptides 9: 583-588

17. Rushakoff RA, Goldfine ID, B eccaria LJ, Mathur A, B rand R J, Liddle R A (1993) R educed postprandial cholecystokinin (CCK) secretion in patients with noninsulin-dependent diabetes mellitus: evidence for a role for CCK in regulating postprandial hyperglycaemia. J Clin Endocrinol M etab 76: 489-493

18. G lasbrenner $B, D$ ominguez-M unoz $E$, $R$ iepl $R L$, Vetsi $A$, Malfertheiner $P$ (1995) Cholecystokinin and pancreatic polypeptide release in diabetic patients with and without autonomic neuropathy. D ig D is Sci 40: 406-411

19. G uan D, Phillips WT, Schwartz J G, Paul E, Rehfeld J, G reen GM (1995) Plasma CCK and secretin levels are elevated in type II diabetes. G astroenterology 108:A 973 (A bstract)

20. Baile CA, M CLaughlin CL, Moos A B (1982) E ffects of $C C K$ on gastrointestinal function in lean and obese $Z$ ucker rats. Peptides 3: 619-622

21. M CL aughlin CL, Peikin SR, B aile CA (1982) D ecreased pancreatic exocrine response to cholecystokinin in Z ucker obese rats. A m J Physiol 242:G 612-G 619

22. M CL aughlin CL, Baile CA (1980) D ecreased sensitivity of Zucker obese rats to the putative satiety agent cholecystokinin. Physiol Behav 25: 543-548

23. G reen GM (1994) Feedback inhibition of cholecystokinin secretion by bile acids and pancreatic proteases. In: R eeve J R, E ysselein VJ, Solomon TE, G o V L W (eds) Cholecystokinin, vol 713. N ew Y ork A cademy of Sciences, N ew Y ork, pp 167-179

24. L u Y , O wyang C (1995) Secretin at physiological doses inhibits gastric motility via a vagal afferent pathway. A m J Physiol 268:G 1012-G 1016

25. R aybould HE, Tache $Y$ (1988) Cholecystokinin inhibits gastric motility and emptying via a capsaicin-sensitive vagal pathway in rats. A m J Physiol 255:G 242-G 246

26. G ainsborough N, M askrey VL, Nelson M L, et al. (1993) The association of age with gastric emptying. A ge and A ging 22: 37-40

27. M aerz LL, Sankaran H, Scharpf SJ, Deveney CW (1994) $\mathrm{E}$ ffect of caloric content and composition of a liquid meal on gastric emptying in the rat. A m J Physiol 267:R 1163R 1167

28. Young A A, G edulin B, V ine W, Percy A, Rink TJ (1995) $G$ astric emptying is accelerated in diabetic $B B$ rats and is slowed by subcutaneous injections of amylin. Diabetologia 38: 642-648

29. H iramatsu S, I noue K, Sako Y, U meda F, Nawata H (1994) Insulin treatment improves relative hypersecretion of amylin to insulin in rats with non-insulin-dependent diabetes mellitus induced by neonatal streptozocin injection. Metabolism 43: 766-770

30. B utler PC, Chou J, Carter W B, et al. (1990) E ffects of meal ingestion on plasma amylin concentration in NIDDM and nondiabetic humans. D iabetes 39: 752-756

31. Schwartz J G, G reen G M, G uan D, Phillips WT (1994) Treatment with an oral proteinase inhibitor slows gastric emptying and acutely reduces glucose and insulin levels following a liquid meal in type II diabetic patients. Diabetes Care 17: 255-262

32. G ulli G, Ferrannini E, Stern M, Haffner S, D eFronzo R A (1992) The metabolic profile of NID D M is fully established in glucose-tolerant offspring of two Mexican-A merican NID D M parents. D iabetes 41: 1575-1586 